\title{
Representation of 'family' in indian television serials
}

\section{DOI: http://doi.org/10.26758/8.1.22}

Gudipaty Nagamallika

The English and Foreign Languages University, Hyderabad, India

Address correspondence to: Gudipaty Nagamallika; email: nagamallika.gudipaty@gmail.com

\begin{abstract}
Objectives. Effects of globalization have been limited in relation to Indian family structure and culture. Television, an important source of infotainment for most Indian households, reflects social reality with real-time, tempered with elements of drama and stereotypical depictions of characters within families. This paper analyses family as a unit, a universal theme in most television serials, its inter and intra family relationships and extent of dramatic liberty to overcome the limitations of a serial's life.

Material and methods. Ethnographic content analysis of the top ten Hindi serials (national language of India) of 2016 (based on Broadcast Audience Research Council, India) was conducted with main characters within family as the unit of analysis. Descriptions of protagonists and the power equations determine the relationships and hierarchies within television families. Categories that emerged from the narratives using grounded theory were: structure of the family, the power centers within the family, the portrayal of 'good' and 'evil' and its relation to power equations within the family members.

Results and Conclusions. As a descriptive study, the results obtained reflect the conclusions. Rich, upper-middle-class joint families are still the most popular institutions in television serials and women continue to be dominant forces in soap operas. A shift in the importance of characters within the family fold incorporates the changing dynamics in the current Indian society. The naturalization of 'supernatural beings' in the family serials helped overcome the temporal and spatial limitations of an ordinary serial, a trend reflecting global agenda.
\end{abstract}

Keywords: joint family; matriarch; supernatural beings; serials.

\section{Introduction}

Television entered India in 1959, but it was only after the telecast of Asian Games in 1982 in color, that television became popular commercially. Initially, Doordarshan, the public broadcaster under the government of India had a virtual monopoly over the television market. Economic liberalization from the ' 90 s increased the number of private channels, now over 883 , widening the scope and growth of technological as well as programming content. Today, there are over 600 million viewers in 146 million homes with television channels and a market estimated to be worth 588 billion INR. (913 million USD) (KPMG-India, 2016). There are specialized channels ranging from entertainment to sports, children, and news but the general-interest entertainment channels (GEC) in Hindi and regional languages dominate the television market with around 55\% 
viewership (KPMG-India, 2016). The general entertainment channels (GEC) space accounted for 8 out of 10 top prime-time shows in 2016 (KPMG-India, 2017) of which family-based soap-operas or serials form a major part. Soap-operas that began as weekly serials telecast on Doordarshan in the ' 80 s, turned into daily serials with the entry of $24 \times 7$ private television channels in the ' 90 s. Since then, the competition has been fierce in a fragmented market, rapid growth in the number of channels and regionalization; conversely, this leads to an increase in the number of soap-operas (Lecuyer, 2013). The serials one find on television in India today fit the Webster's dictionary definition of a soap opera: 'serial drama performed originally on a daytime radio or television program and chiefly characterized by tangled interpersonal situations and melodramatic or sentimental treatment'. The longest series in the history of Indian television, Kyunki Saas Bhi Kabhi Bahu Thi, (Because the mother-in-law was a daughter-in-law once) was aired for 8 years and 8 months, amounting to 1,830 episodes. It has been the most-watched series in Asia, maintaining twofigure audience ratings for over 5 successive years with over the 110 million viewer mark for one of its flagship episodes (Lecuyer, 2013).

The present study analyses television serials from the top ten of the last quarter of 2016 to examine if they reflect the existing socio-cultural conditions and transformations that a country like India with its multicultural milieu exhibits. Do the Indian soap-operas portray the real and/or hidden structures that exist in archetypes or do the mythical narratives of the serials make it possible to exhibit the underlying substructure of various cultural phenomena such as customs, rites, and habits within a social institution represented by a family? In this paper, the terms soap-operas and serials are used interchangeably as there are no distinct differences between them in today's television programs. By serials/soap-operas I mean the daily programs which are aired from half hour to one hour with a storyline that revolves around a family or two for generations, sometimes with a closure and at other times continue for years or pulled off air suddenly keeping in mind the popularity of the program. The scope of this paper is limited to examining only the national language (Hindi) serials.

\section{Changing Structure of Indian families}

Families always form a strong social base in India whether they are joint or nuclear. The dynamic changes in Indian society resulted in the transformation of joint families to nuclear. Traditionally, India had a patriarchal family system with a few exceptions, which follow the matriarchal system (Rao, 2011). Every member of the family had a defined role that was acculturated and socialized into the community. Urbanization and industrialization brought in structural changes within families and villages (Khan and Rizvi, 2015). A consequence of such changes was a large-scale migration to urban areas and conversion of joint families to nuclear (Khan and Rizvi, 2015). The children migrated to the towns and cities in search of jobs with their families, leaving behind the parents; returning annually to visit them. Westernization also led to modernization resulting in education and an increase in women workforce.

The technological leap that India took in the last two decades due to Information Technology resulted in double incomes, the high economic growth of families, and economic independence for women, absent earlier. An interesting outcome of this is a reversal in the structure of nuclear families. According to the Indian census data, the percentage of nuclear families decreased slightly between 2001 and 2011 from $70.34 \%$ to $70.11 \%$. Although the overall number of nuclear families increased (from 135 million in 2001 to 172 million in 2011), it was at a slower pace than the overall population growth (Raja, 2014). The government of India stated that families are increasingly fragmenting in rural areas, but more people in cities are choosing to live in extended 
families. Between 2001 and 2011, joint families in urban India grew 29\%, whereas in rural areas they rose only $2 \%$ (indiatimes.com, 2017).

Concurrently, the family that was the nucleus, around which the Indian society functioned, is undergoing changes with an increasing number of cases of divorce and separation, single parents, and people marrying late or opting to stay single; (Raja, 2014) mostly experienced in the urban metros. They may opt to stay with parents or siblings or children leading to 'sub-nuclear units' (indiatimes.com, 2017). Such developments have not completely disintegrated the notion of a defined family but led to a new kind of hybrid family structure as most nuclear households continue to exist as constituents of joint families (Mondal, 2016). With parents working, the grandparents stay home to take care of the children. Not many parents opt for commercial arrangements as the traditional notion of familial roles have not been discarded. Another reason is the financial burden such arrangements involve. According to TV Sekher, a professor at the International Institute of Population Studies (IIPS) in Mumbai, "In urban areas, with the scarcity of housing, there is a tendency of families to stay together" (Raja, 2014). It is economical to revert to a joint family setting than stay nuclear. However, the traditional structure and roles of members within a joint family system changed as the children do not live with the parents but vice versa, where the parents stay as 'guests' and not as 'heads' of joint family. It is more of a democratic collective than autocratic; as individual freedom and independence is guaranteed with economic limitations and emotional needs binding them (Ruchismita, 2012). In the case of rich and/or business families' preference for joint families, involving the family members in their business, has increased. The support system and the economic compulsions of keeping the family business intact are the prime reasons. However, the extent of autonomy and democracy may vary from region to region, community to community and caste to caste, depending upon the degree of its adaptation of the modern values and the urban way of life (Mondal, 2016).

\section{Indian family in television serials}

The family is one of the most popular social institutions represented in television serials to depict the social 'reality'. But do television serials construct the notion of 'reality' while fulfilling the features of a dramatic 'theatrical' through their narratives is the question that needs to be answered.

From being a mediator of reality, television has come to construct reality. Television soaps may have created a reality and culture that transformed the idea of an Indian family. The families on the shows may not be realistic, but they do remain relatable to a certain extent although the depiction might take certain liberties with sensational content and larger than life characters and the high drama. The melodramatic component of a television serial within the format of realistic portrayal of families become specific features of serials that condition the treatment of certain issues in contemporary social problems (Geraghty, 1991).

A pan Indian notion of a joint family, upper class, rich and heading huge business empires has become the stereotypical image of Indian families on television, subsuming the diverse cultures represented by different classes, regions, and castes which is the reality. The social representation of a family and the power, authority and status that some members hold, as depicted in soaps, may not necessarily reflect the existing family structures or cultures. However, the soaps continue to hold sway over a majority of viewers who watch the family dramas as they might have accepted the new normal in a dynamic socio-cultural setting.

The television family's depiction of Indian societal values has undergone changes in the last two decades - with a dilemma between modernity and tradition - much like the family systems 
in India. In the ' $80 \mathrm{~s}$, when the early television serials were produced, they were quite different from the regular soaps of the west. The initial serials aired by the public broadcaster Doordarshan were modeled on the Latin American soap-operas which dealt with identity and treatment of social issues. Serials like Hum Log (1984) (We the people) discussed issues of health, schooling, family planning, education and others to which the middle class related. The pro-development television soap-operas were melodramatic serials broadcast in order to entertain and to convey subtly an educational theme to promote development (Singhal and Rogers, 1988). The emergence of Hindutva politics in the ' 80 s later influenced the kind of serials made. Serials made on Ramayan (1986) and Mahabharat, (1988) the two Indian epics became very popular, brought in a new notion of Hindu national identity as distinct from the secular. This was followed by the economic liberalization of the '90s, coupled with the rise of Hindutva, became the predominant factor to hegemonically characterize these notions (Lata, 2016). The socio-economic-political scenario reflected in the changing patterns of storylines, in turn influencing the notions of family, gender, and nation (Lata, 2016). The interplay between tradition and modernity is usually evident in the storylines that deal with child marriages and the stereotypical representation of the Indian women in their familial roles, to which a recent addition has been supernatural mythical tales, however, set in modern urban backdrops like marble mansions and opulent sets and relationship patterns that are modern in their approach.

\section{The mythical and the social institutions in Indian serials}

With TRPs driving the storylines, the latest development in Indian televisions serials is the entry of supernatural elements into family plots. As Lévi-Strauss says, myths have the dual nature of submitting to time and transcending time, which makes it both temporal and atemporal (Casalis, 1974). This serves the purpose of the serials that regularly transcend time by jumping decades and now took a bigger leap of bringing in characters from the world beyond like devils, ghosts, and witches. The myth is a logical tool to overcome contradictions (Casalis, 1974) and the serials have used this 'tool' to overcome the many contradictions that an open-ended program encounters. The introduction of paranormal elements into family settings in the serials has served the purpose of overcoming the limits set by the 'ordinary'. Today, the Naagins, (Snakes) Daayans, (Witches) and Shaitans (devils) are more popular than shows that deal with human beings alone as the paranormal elements symbolize the existence, logic, and justification of some of the beliefs and values within the Indian cultural milieu apart from being interesting. Black magic and witchcraft form part of the 'mythical normality', as such issues, relatable especially in rural areas are part of social reality. People lynched or killed on suspicion of practicing witchcraft and black magic has been reported and form part of the larger symbolic cultural practices even today. So combining a myth (traditional eastern thought of anamnesis of mythical events) within a tale (a western notion of historical time) (Eliade, 1963, p.138) overcomes the limitations of both and acquires their collective strengths. This leads the serials to overcome logic and acquire more freedom and arbitrariness in molding their storyline and characters. As Lévi-Strauss (1976, p.128) says, 'anything becomes possible with myth' making it therapeutic by projecting the hidden social repressions not otherwise visible in the everyday reality.

Just as the werewolves and vampires work in the West, Naag, (snakes) Naagin, (snake woman) tantra, and kala jaadu (black magic), work in India, as both of them demonstrate the cultural variants as per their social understanding of the world. "The fantasy-fiction genre attracts a lot of young viewers, and it takes you away from the mundane. That's why historical and mythological dramas work too. These supernatural elements are part of our culture" according to a television actress (Awaasthi, 2016). As Ekta Kapoor, a famous television producer said, "The target 
audience for all these (supernatural) serials are the rural consumers as the urban youth do not watch Indian television as they are hooked to American fantasy genres like the Twilight series and Game Of Thrones (GOT)" (Awaasthi, 2016). Women and kids in rural households regularly watch the TV shows and the producers and broadcasters cater to this demand. The Broadcasting Content Complaints Council issued an advisory to channels to exercise caution and restraint while airing such shows, as the horror and occult tracks propagate superstition. But channels defend themselves with disclaimers on their shows (Awaasthi, 2016).

\section{Methodology}

Research method of Ethnographic Content Analysis (Altheide, 1987) has been adopted to analyze the top ten Hindi (national language of India) shows based on the viewership ratings as per Broadcast Audience Research Council, India (BARC). Of these, one comedy show was not considered for analysis, as it did not fit into the main theme of family. The other nine are serials running between 2010 and 2016. Ethnography refers to the description of people and their culture (Schwartz and Jacobs, 1979) with in-depth observations of the researcher who forms part of the research tool. Content analysis deals with the objective content of written and electronic documents to verify hypothetical relationships with a positivistic approach. Although television serials reflect exaggerated aspects of culture, they form an integral part of the cultural conundrum of modern societies. As a regular viewer one is drawn into the dilemmas and conflicts of the television family comparable to the 'fly on the wall' as one identifies with the issues. So an Ethnographic Content Analysis is holistic as a methodology as it documents and communicates meanings to verify theoretical relationships where the meaning of a message is assumed to be reflected in various modes of information exchange, format, and style as well as in the context of the text (Altheide, 1987); in this case, television serials. As family forms a cultural unit, it is meaningful for a reflexive study of one particular aspect of culture, which is the family, in the context of Indian television culture. From the detailed viewing of the serials selected, the following themes that recurred were selected for a descriptive analysis: family structures, the power centers within the family and the portrayal of 'good' and 'evil' and the power equations within each serial. The meaning that was communicated of the people involved in the families through their exchange, the format and the context in which the serials were set were described through the analysis. Only the family units and the predominant relations that are visible under each theme were considered but not individual episodes. The top ten serials considered were: Naagin, 2 (Snake Woman Season 2) Kumkum Bhagya, (Vermillon in my destiny) Saath Nibhana Saathiya, (Be with me friend/partner) Naagin, (Snake woman- repeat of previous season), Shakti, Astitva ke Ehsaas ki, (Strength Of Feeling Of Existence) Kapil Sharma show (Kapil Sharma's show), Sasural Simar ka, (Simar's Inlaw's house) Yeh hai mohabbatein, (This is love) Ishqbaaaz (Lovers) and Brahmarakshas (Demon).

\section{Brief storylines of the serials}

1. Naagin 2 (Snake woman): is the story of two sisters who are shape -shifting serpents. The story continues from Season 1. (storyline is described below under Naagin Season 1). The popularity of the supernatural genres is established by the fact that the repeat telecast of Naagin (Season 1) has also found place in the top ten most popular programs with high TRP ratings. This is the first time that a serial is being shown in seasons and not continuously. 
2. Kumkum Bhagya (Vermillion in my Destiny): The show is loosely based on the novel Sense and Sensibility by Jane Austen. Kumkum Bhagya is its Indian interpretation, which follows the life of a Hindu-Punjabi matriarch, Sarla Arora, who runs a marriage hall. Sarla lives with the hope of seeing her two daughters Pragya and Bulbul, happily married some day. The pivotal characters of this show are strong, feisty women, living together in an all-female matriarchal family. The show follows the lives of the two sisters and their hopes, dreams, and aspirations. It takes several twists and turns as one of the sisters Bulbul dies. Pragya a simple serious working girl gets married to Abhi, a rock star. Later on, he loses his memory in an accident and forgets her. His sister and her friend who wants to marry Abhi try in several ways to separate them.

3. Saath Nibhaana Saathiya (Be with me friend/partner): Began telecast in 2010 and is still popular. The series revolves around the fictitious Modi family, who live in a mansion in Rajkot. The show explores morals and family values of a typical Gujarati joint family. Initially, the show focused on the life and arranged marriage of two female cousins (Gopi and Rashi) and their contrasting personalities. Urmila and Jitu adopt Gopi (the latter's niece) after Gopi's parents pass away; she is left illiterate, naive, kind and shy while Rashi, their own daughter, is educated, outgoing, vivacious and cunning. It is the story of how Kokila Modi - the strict, strong-minded mother-in-law of Gopi, transforms the latter into a confident and smarter woman so that she gets accepted by her husband. Rashi tries numerous unsuccessful attempts to create difficulties for Gopi, but, in the end, both cousins get accepted into their families and by their spouses. The storyline took a leap of eight years in February 2014, a further leap of ten years in March 2015, and a final leap of four years in May 2016, which brought in many changes. Saath Nibhaana Saathiya has been made in several different Indian languages. Internationally it airs in Sri Lanka dubbed into Sinhala.

4. Naagin (Snake Woman): The first season of the serial became popular and is having repeat telecast in Season 2 and is in the top ten. This is the story of two shape-shifting serpents, or Ichchhadhari Naagins - Shivanya and her cousin Shesha. They want to avenge Shivanya's parents' death. There were five murderers, but Shivanya sees only three of them: Ankush, Viren and Shailesh. They kill Shivanya's parents in a failed attempt to attain a precious gem called the Naagmani. As part of her revenge, Shivanya enters Ankush's house as a maiden. Ankush's son Ritik, a kind-hearted young man, subsequently falls in love with her. Upon finding out about Ritik's feelings for her, Shivanya marries him for revenge. Later, she kills Viren (the first murderer) and Shailesh (the third murderer); Shivanya and Shesha also kill Ankush's friend, Suri, who is the fourth murderer. Shivanya realises that Ritik is a good person, and eventually falls in love with him, much to the disappointment of Shesha, who thinks that Shivanya won't be able to kill Ankush (second murderer) because of her love for his son, Ritik.

5. Shakti, Astitva ke Ehsaas ki (Strength in the Feeling of Existence): The story is about two sisters, Soumya and Surbhi. Soumya is not liked by her father and grandmother but is adored by her mother. Surbhi gets all the attention from her father. Soumya is a calm and quiet girl, but Surbhi is a fun-loving and loquacious girl. Soumya is shocked to learn that she is transgender and attempts suicide but is rescued by Harman who wants to marry her. But later she learns that she is not a transgender.

6. Kapil Sharma show: This is the only non serial that made it to the top ten. It is a comedy show hosted by Kapil Sharma a standup comedian who invites guests to his show and interviews them. 
7. Sasural Simar Ka (Simar's in-law's house): It tells the story of two sisters, Roli and Simar, who fall in love with two brothers, Siddhant and Prem, and live together as daughters-in-law in the Bharadwaj household. The story takes three leaps. After the first leap, the story revolves around supernatural creatures and evil spirits who come to destroy the Bharadwaj family. The first one is Maya, an Icchadari Naagin (Snake Woman). Then, a Daayan (witch) named Mohini comes to destroy the Bharadwajs. Simar (the heroine) kills the witch. Next, the witch's spirit, Indrawati (who was Simar's sister in her previous life) comes to Simar's house and wants to marry Prem, Simar's husband, but is killed by Simar. Next enters an evil goddess named Patali Devi who comes to take revenge on behalf of Indrawati and Mohini (both witches) from Simar but her spirit is captured in a statue. Devika, a fairy godmother, gives Simar a Chandramani (a precious stone) for her safety from all the evil spirits.

8. Yeh hai mohabbatein (This is love): The show follows the love story of Dr. Ishita Iyer, who is a Tamilian and Ramankumar Bhalla, who is a Punjabi. Ishita is unable to bear a child and so gets emotionally attached to Raman's daughter, Ruhi, who lives with her divorced father. Raman's exwife, Shagun, lives with her boyfriend and Raman's ex-boss Ashok Khanna, along with her son with Raman, Aditya. Bhallas and Iyers are neighbors. Due to circumstances, Raman and Ishita marry each other for Ruhi's custody and gradually fall in love with each other and lead a happy life. The story also takes a leap of 7 years where Ishita conceives but later on misunderstandings between Raman and Ishita leads to their separation.

9. Ishqbaaaz (Lovers): The story is about the lives of a rich business family, the Oberoi family who face difficult and challenging situations from time to time. The family consists of two brothers and their wives. The elder brother Tej has a wife, Jhanvi who is an alcoholic addict, because of Tej's illicit affair with his secretary, Svetlana. Tej and Jhanvi have three children. Their eldest son Omkara is a sculptor and a self-made billionaire but a drug addict. Tej and Jhanvi's second child, Rudra, is a playboy and loves partying but does not believe in marriage. They also have a daughter, Priyanka who is a quiet, sweet and simple girl who has social anxiety disorder. Tej's younger brother, Shakti has a wife Pinky and a son, Shivaay, who is the eldest son and the face of the Oberoi's industry. He is a business tycoon with a strict personality that matches his uncle, Tej. He is arrogant, snobbish and judges people on the basis of their lineage and social status, rather than their personality or work.

10. Brahmarakshas: Jaag Utha Shaitaan (Demon: the devil rises): The story of Brahmarakshas revolves around a young girl Raina who comes to a small village Kamalapura for a wedding, completely unaware of the existence of Brahmarakshas (demon). The demon kills newly married brides who wear the sindoor (vermillon worn in the hair parting) chooda (bangles) and mangalsutra (a chain worn by married women) (all symbols of being married). Raina gets into a contract marriage with Rishabh to fight the demon; later they have differences and separate but Raina continues to fight the evil demon.

\section{Analysis}

The analyses of the serials' formats, the style, and context in which the family is presented elicited certain common features. For instance, all the serials selected except Naagin $1 \& 2$ were aired continuously for the past six years. Unlike the west, the serials do not follow the seasons, but are featured all round the year; so Naagin set a new trend. All the serials followed the long form 
narratives where the stories unfold over the years and generations with leisurely storytelling. The serials are heavily influenced by the Indian film formats of elaborate sets, photographic angles, costumes, heavy dialogues and song $\&$ dance sequences. They all telecast using real-time; festivals coincide with real festivals and other rituals like birth, death, weddings, and poojas performed at home and in temples showcase the traditional Indian family making the viewer an observer as well as a participant. The characters dress in traditional clothes of a particular region the serial represents. For example, in Brahmrakshas (Demon) entire episodes are devoted to the wedding of the protagonist, who is adorned with vermillion, bangles, and chain dressed in red that symbolizes North Indian tradition. The demon kills any newlywed woman attired in red. The spoken language although Hindi, (the national language of India), retains the flavor of the region. For example, if the serial depicts a family from Uttar Pradesh or Gujarat, Hindi with an intonation of that particular province is used. This ensures that while the language is understood widely, the region is also represented. In states (provinces) that do not understand Hindi, the serials are dubbed in the local language. In this sense, television homogenized Indian culture, which in reality exhibits a variety of subcultures. The settings and the visuals represent the lifestyle of the upper middle class/ rich which most families aspire to reach while the plots cater to the rural audiences with storylines based on supernatural beings, to kill or send someone away from the family fold with clearly marked differences between the protagonist and antagonist through dressing, expressions, and dialogues. These serials draw clear distinctions between the urban and rural audiences. The distinction between the wealthy and the rest is also clearly established through the opulent settings, female characters attired in silks, bedecked with jewelry and the males in suits. In all, the settings resembling houses of the rich and famous in India, with the layered plots and the devilish scheming characters that add to the element of melodrama, make up the schema/context of Indian televisions serials. Currently, the majority of the selected serials (7/10) has adopted fantasy elements with supernatural beings becoming part of a modern family. Such elements are introduced from past lives and/or possession by spirits which Indian philosophy steeped in theism and animism find acceptable. Folklores also form an important part of Indian culture, which is now being incorporated in the storylines. A fine balance between tradition and modernity is achieved as the themes deal with social issues, but the settings, characters, and solutions are most often mainstream. For example, in a serial called Shakti, Astitva ke Ehsaas ki (Strength in the Feeling of Existence), a social issue like transgenders and their acceptance in society is taken up, with the heroine being a transgender, but falls back on the majoritarian view, declaring that she is in fact 'normal'. Similarly, Yeh hai mohabbatein (This is love) deals with divorcees and Saath Nibhaana Saathiya (Be with me friend/partner) deals with the importance of adult education although they revert to formulaic narratives in the latter episodes.

The following themes emerged after viewing the data in which the interpretation was more reflexive than objective. This helps to arrive at a theoretical understanding of the meaning in the depiction of family relations in television serials.

\section{Structure of the family}

All the serials selected for the study depict a family unit with stories revolving around family members. From the various characters introduced over the years, and their relationship with the central characters it becomes clear that all families are extended families with two or three generations living together under one roof. For instance, in all serials, there are grandparents, parents, uncles, aunts, and their children- the nephews and nieces- living together. Most television serials portray the rich and the powerful in a joint family. This kind of structure within such genres is important more so to carry the open-ended narratives forward, aired for long intervals of time. 
Interestingly, in recent times, it is found that many of the rich business families in India prefer the modern kind of joint family system where the extended family stays together but there is more involvement of youngsters in decision-making (Prasad et al., 2010), unlike the traditional patriarchal joint family system. In a nation where almost $90 \%$ of the population falls below the poverty line at the global level and only $1 \%$ form the so-called rich or upper-class Indian families (The Hindu, 2017), the television families do not represent an average Indian family. However, the serials form a good basis for the growing aspirations of the middle-income families in India to be part of the privileged society. Keeping with the tradition of women dominating the serials or soaps, it is the matriarch that usually heads the family. The story takes off from the childhood or adolescence of the main protagonist and with all serials taking leaps across years, follow them to their middle age.

\section{The power centers within the family}

A common phenomenon worldwide is the dominance of female characters in television soap-operas. It is the same with the Indian television serials with the dominance of female members unlike the real-life Indian families, which are, in general, patriarchal. One finds that, if the television family is headed by the grandmother, she will be a matriarch, but if it is a man, he is dominated by his wife or daughter-in-law. The plots of the early serials in the '90s and early 2000s, famous for the mother-in-law daughter-in-law skirmishes now shifted to the daughters of the house, with two sisters as their protagonists and/or antagonists typically plotting against her/his sister/brother. This also symbolizes the shifting family structures in India where the domination of the older generation in joint families has decreased. Those in power are the ones who control the rest of the family, be it good or evil. Even the male member falls in line with the dictates of the one in power however unreasonable the behavior might be. For instance, in Kumkum Bhagya, (Vermillion in my Destiny) even though Abhi, husband of the protagonist Pragya is about to get married to another girl due to the machinations of Abhi's sister, (as he loses his memory) no one will stop it or reveal the truth to him, including his wife. Similarly, in Saath Nibhaana Saathiya (Be with me friend/partner), Gopi is the protagonist who is punished with life imprisonment on wrong charges of murder again due to her sister. It is the female who is the power centre in most of the serials like Kumkum Bhagya (Vermillion in my Destiny) where Sarla, mother of Pragya runs a marriage hall; there is Gopi's mother-in-law Kokila who is the matriarch in Saath Nibhana Sathiya (Be with me friend/partner); with Gopi in the next generation. We also have the female serpent-woman who is the center of power in Naagin (Snake woman) while in Brahmarakshas (Demon) it is the heroine Raina who continues to fight the evil. Though there are stories of brothers like Ishqbaaaz, (Lovers) they are in the minority. One can also argue that the supernatural elements in the serials imply the manifestations of the hitherto hidden presence of power and control.

\section{Portrayal of 'good' and 'evil'}

A decade ago, in the 2000s, the 'mother-in-law and daughter-in-law' sagas were popular with the mother-in-law or the sister-in-law personifying 'evil' with all efforts to control and wrest power, while the 'good' obedient suffering daughter-in-law was targeted and tortured. Every serial's plot moves forward only through the struggle between good and evil, more so in Indian television serials where melodrama reigns supreme. There has been a difference in the portrayal of 'good' and 'evil' in the last couple of years in Indian television. The manifestation of evil in humans, apparent in their behavior patterns and exchanges between characters and acts now exhibit a more overt form as supernatural beings. The demons and spirits defy the limitations of the human being. The 
retribution of the evil is no longer easy as the protagonist now has to take on extra-terrestrial beings with supernatural powers. Exorcising the demons made powerful with black magic has become a part of many serials that can find an identity in the rural masses. But the tradition of good winning over evil continues.

Technology has been the key element that made such exposition simple and cost-effective. Even the serials with modern themes initially, veer towards the supernatural after some episodes due to the compulsions of competition and advertisers. For instance, the serial 'Yeh hai Mohabattein (This is love) which began with two divorcees (a progressive theme in India) took off on a tangent with the heroine Ishita becoming possessed with Raman's (her husband) ex-wife, Shagun's spirit after the latter commits suicide. Similarly, in another serial Sasuraal Simar Ka (Simar's In laws' house) various supernatural beings like a snake woman, a witch, and devil were introduced into a normal modern household. Since then, the ratings of the show improved. The latest twist upped the quotient by turning the protagonist, Simar, into a housefly and she gets pregnant with a devil's child. Similarly, in Naagin land 2 (Snake Woman), the heroine who is a shape-shifting snake, takes revenge on her parents' killers. This is the first of the supernatural themes whose popularity spawned serials with similar storylines. With the trend in Hollywood and Bollywood (Hindi films) moving towards aliens and paranormal themes, it is a natural consequence to see more plots and storylines based on such themes. Simultaneously, there has been an increase in the number of mythologicals, with deities and Gods depicting both good and evil, which also embody the magic and supernatural power of superhuman beings, an accepted genre in Indian culture. Further, the present Government in power espouses its ideology with a clear emphasis on the 'rich, ancient Indian culture and tradition', which includes mythologies and the vast pantheon of Gods. This reflects Strauss's argument that the myths and the social structures of kinship are contextual. The text in this instance should be understood within the context of the socio-political trends in society today as well as the cultural milieu of India that dictates the mythical explorations of the serials being aired currently.

\section{Conclusions}

The analysis shows that television families do not necessarily reflect the true Indian family structures as there is a homogenization of the family as a cultural entity. The matriarchal domination, the joint nature of families or their economic class only serve to meet the needs of an aspirational class. However, globalization has had an effect as power centers shifted to those having financial control. With the younger generation becoming the earning members, there has been a change in the real world with the 'nextgen' having a say in family matters. This reflected within the television families with a shift in the focus on the younger generation with access to more power and consequently centers of conflict. The shift towards fantasy and mythology can be attributed to globalization too with ease of access to technology and Hollywood content. Technology is being used in the creativity front while the fantasy elements in the content are Indianised to suit the sensibilities of the Indian audience.

To sum up, the plots and characters within the serials have been defined by the changing profiles of the audience in a changing socio-political atmosphere, from the first serial aired nearly forty years ago until now. Theoretically speaking, the storylines of the television serials can be divided into four phases, which reflect how a common man can identify with a character or a serial identification, aspiration, distinction (Sahu, 2014) and fantasy contextually.

In the first phase, Doordarshan as the public broadcaster was the only source of teleserials, with emphasis on development, featuring middle-class families to discuss issues familiar to 
them. The Indian audience, which believed in the socialist development model, could identify with these serials. Economic liberalization in the '90s brought in the entry of private television channels signaling the beginning of competition to a hitherto monopolistic Doordarshan.

The immensely popular family drama Kyunki saas bhi kabhi bahu thi (Because mother-inlaw was a daughter-in-law once) aired in 2000 heralded the second phase in the history of television serials post liberalization. The characters satisfied the urban middle-class Indian audiences' aspirations to be like the onscreen characters that were modern in a capitalistic society without losing sight of the traditional morality and Indian values. The formula lasted for decades because it put identifiable characters into aspirational settings (Stanley, 2012).

During the third phase, in the latter half of the 2000s, the audience base widened with the penetration of private television market into rural areas and subsequently a rise in regional language channels. The plots of serials being aired changed slightly to suit the changing demographics. The rich business families continued to dominate but the plots began to incorporate the rural rich, set in rural areas. The focus shifted from the bahus (daughters-in-law) to betis (daughters). They dealt with issues like child marriage, female foeticide, widow remarriage, girl education, dowry harassment etc. While the rural audiences could identify with the stories, the urban audiences were curious to see issues distinct from their experiences, which held their interest. By this time, the entry of online media and web access to the urban audiences made television a secondary source of entertainment. The intense competition and the changing audience profiles made the television serials structure their stories to suit them.

The fourth phase has been the introduction of fantasy into the narratives through supernatural beings in modern family dramas, which is reflected in the serials selected for the study. The effects of globalization have not escaped the trends in televisions serials too. As the West is veering towards the supernatural and the paranormal, the Indian films and television serials have not been far in incorporating such themes into family dramas. The plots have introduced elements of the supernatural like witchcraft, black magic, devils, snake women, etc., which are contextualized to suit the Indian audience and the social mores. The rural audiences relate to such paranormal themes as the serials continue to hold their interest showing social fears, stigmas, and beliefs. At the same time, their aspirations are met through the modern settings and rituals based on religious beliefs like festivals and weddings.

Despite the changing plots that accommodate the mythical and the real, the traditional and the modern, the central themes of family-based serials in Indian television remain centered around the family where women dominate the narratives, as they continue to entertain and capture the imagination of a large section of the Indian audience.

\section{References}

1. Altheide, D.L., 1987. Reflections. Ethnographic Content Analysis. Qualitative Sociology, 101(1), pp.65-77.

2. Awaasthi, K., 2016. Supernatural creatures to shape shifting animals: How low will Indian TV go? Hindustan Times, June 30. Available at: $<$ http://www.hindustantimes.com/tv/supernatural-creatures-to-shape-shifting-animals-how-lowwill-indian-tv-go/story-ChpUj1ViP4HwYuTTIgjG4N.html> [Accessed 6 June 2017].

3. Casalis, M., 1974. Levis-Strauss Structural Analysis Of Myths: A Study In Methodology. Southwest Philosophical Studies by New Mexico-West Texas Philosophical Society. Available at: 〈http://nmwt.org/nmwt/?r=article/view\&id=421> [Accessed 18 July 2017].

4. Eliade, M., 1963. Myth and Reality, New York: Harper and Row. 
5. Geraghty, C., 1991. Women and Soap Opera: A Study of Prime Time Soaps. Cambridge, UK: Polity Press.

6. Khan, N. and Nuzhat R., 2015. Urbanization and Its Effect on Joint Family System In India. International Journal on Recent and Innovation Trends in Computing and Communication [online] February. 3(2), pp. 154-6. Available at: < http://www.ijritcc.org> [Accessed 16 July 2017].

7. Lata, K., 2016. Family, Gender And Nation in Indian Television serials. A sociological study of Hindi soap operas. UK: Lambert Academic Publishing.

8. Lecuyer, H., 2013. Soap operas dominate prime-time television in India. Ina Global, 16 May. Available at: <http://www.inaglobal.fr/en/television/article/soap-operas-dominate-prime-timetelevision-india > [Accessed 16 July 2017].

9. Lévi-Strauss, Cl., 1976. Structural Anthropology, Vol II, New York: Basic Books.

10. Mondal, P., 2016. Recent Changes in the Family System in India. Yourarticlelibrary.com. Available at: <http://www.yourarticlelibrary.com/essay/recent-changes-in-the-family-system-in India/30751/> [Accessed 16 July 2017].

11. Prasad, S., Nath, S. and Ramnath, N.S., 2010. Indian Family Businesses. Forbes. 22 October. Available at: < https://www.forbes.com/2010/10/22/forbes-india-indian-family-businesses-turnto-professionals.html $>$ [Accessed 16 July 2017].

12. Rao, S.C.N., 2011. Sociology: Principles of sociology with an introduction to social thought. 6th Edition. New Delhi: S. Chand \& Company Ltd. pp. 353-359

13. Raja, D.J.S., 2014. Actually, the nuclear family is on the decline in India, Quartz India, 1 July. Available at: <https://qz.com/228405/india-is-urbanizing-rapidly-but-the-nuclear-family-isactually-shrinking/ [Accessed 16 July 2017].

14. Ruchismita, 2012. Is the Joint family system in India disintegrating? Preserved articles.com. Available at: <http://www.preservearticles.com/2011111517230/is-the-joint-family-system-inindia-disintegrating-essay.html > [Accessed 17 July 2017].

15. Sahu, S., 2014. Making sense of TV soap operas: a study of audience response. Ph D thesis. Unpublished 26-September. Sodhganga. Available at: http://shodhganga.inflibnet.ac.in/handle/10603/26088 > [Accessed 17 July, 2017)

16. Singhal, A. and Rogers, E.M. 1988. Television soap operas for development in India. Gazette, 41, pp.109-126. Dordrecht: Kluwer Academic Publishers. Available at: < http://utminers.utep.edu/asinghal/Articles\%20and\%20Chapters/JA\%20Singhal\%20\&\%20Rogers \%201988\%20Gazette_R.pdf> [Accessed 6 June, 2017]

17. Stanley, A., 2012. As India's Soap Opera World Turns, Mother-in-Law Always Reigns. The New York Times, 25 December. Available at: 〈http://www.cnbc.com/id/100339141> [Accessed 6 June, 2017].

18. Schwartz, H. and Jacobs, J., 1979. Qualitative Sociology. New York: The Free Press.

19. ***indiatimes.com 2017. Why joint families are back in urban India? Times of India, 16 July. Available at: <http://timesofindia.indiatimes.com/home/sunday-times/why-joint-families-areback-in-urban-india/articleshow/59614752.cms > [Accessed 7 June 2017].

20. ***The Hindu, 2017. Richest $1 \%$ own $58 \%$ of total wealth in India: Oxfam. PTI. Davos, 16 January. Available at: 〈http://www.thehindu.com/business/Economy/Richest-1-own-58-of-totalwealth-in-India-Oxfam/article17044486.ece> [Accessed 8 December, 2017].

21. ***KPMG India - FICCI, 2016. The Future: Now Streaming. Media and Entertainment Industry Report. Available at: <https://home.kpmg.com/content/dam/kpmg/pdf/2016/04/The-Future-nowstreaming.pdf $>$ [Accessed 7 June 2017]. 
22. ***KPMG India - FICCI, 2017. Media for the masses: The promise unfolds. Media and Entertainment Report. Available at: 〈https://assets.kpmg.com/content/dam/kpmg/in/pdf/2017/04/FICCI-Frames-2017.pdf> [Accessed 8 June 2017]. 